SHORT REPORT

\title{
Impact of injecting drug use on the interruption of antiretroviral therapies
}

\author{
R Muga, J M Egea, A Sanvisens, J Arnal, C Tural, J Tor, C Rey-Joly
}

J Epidemiol Community Health 2004;58:286-287. doi: 10.1136/jech.2003.010066

a has been pointed out that HIV positive patients with a history of drug misuse are less likely to undergo antiretroviral therapy (ART) than those who belong to other categories of transmission. ${ }^{12}$ Moreover, inadequate use of ART in injecting drug users (IDUs) is controversial because of the risk of parenteral and/or sexual transmission of drug resistant HIV variants. ${ }^{3}$

The aim of this study was to describe the frequency of use and cessation of antiretroviral regimens over a period characterised by the introduction of highly active antiretroviral therapy (HAART) in Spain.

\section{METHODS}

\section{Patients}

Cross sectional study in HIV positive intravenous heroin misusers consecutively referred to detoxification in a tertiary hospital in metropolitan Barcelona between April 1997 and March 2000. Questionnaires on the characteristics of injecting drug use and history of ART use were administered at entry. Blood samples for HIV (EIA and WB), CD4 cell count, and HIV viral load were collected during admission.

\section{Assessment of antiretroviral medications}

All HIV seropositive people reporting current or past ART use were interviewed by a trained physician and the structured questionnaire included dates of first and successive therapeutic regimens, duration and reasons for discontinuing or abandoning ART (that is, personal decision, side effects, drug failure). The prescribed regimens and dates were confirmed through the hospital pharmacy registry and antecedents of opportunistic infections or malignancies through medical records. We classified use of ART into three categories: none, dual nucleosides, and HAART. Data analysis was carried out using Fisher's exact test or $\chi^{2}$ test.

\section{RESULTS}

Eighty six HIV(+) IDUs (76 men, 10 women) were admitted. Age at entry 32 years (mean); duration of injecting drug use 12.5 years (mean), the self reported duration of HIV infection was 89 months and HIV viral load was 11000 copies/ml

Abbreviations: ART, antiretroviral therapy; HAART, highly active antiretroviral therapy; IDU, injecting drug user

\begin{tabular}{|c|c|c|c|c|}
\hline & ART interruption $\mathrm{n} / \mathrm{N}(\%)$ & OR & $95 \% \mathrm{Cl}$ & p Value \\
\hline \multicolumn{5}{|l|}{ Sex } \\
\hline Male & $22 / 47(47)$ & 1 & - & \\
\hline Female & $7 / 8(87.5)$ & 7.9 & 0.9 to 69.8 & 0.05 \\
\hline \multicolumn{5}{|c|}{ Age at admission (y) } \\
\hline$\leqslant 32$ & $14 / 28(50)$ & 1 & - & \\
\hline$>32$ & $15 / 27(56)$ & 1.3 & 0.4 to 3.6 & 0.8 \\
\hline \multicolumn{5}{|c|}{ Duration of injecting drug use $(y)$} \\
\hline$\leqslant 12$ & $13 / 26(50)$ & 1 & - & \\
\hline$>12$ & $15 / 28(54)$ & 1.1 & 0.4 to 3.4 & 0.9 \\
\hline \multicolumn{5}{|c|}{ Antecedent of incarceration } \\
\hline No & $5 / 14(36)$ & 1 & _- & \\
\hline Yes & $20 / 37(54)$ & 2.1 & 0.6 to 7.5 & 0.4 \\
\hline \multicolumn{5}{|c|}{ Duration of HIV infection } \\
\hline$\leqslant 8$ years & $15 / 30(50)$ & 1 & - & \\
\hline$>8$ years & $14 / 25(56)$ & 1.3 & 0.4 to 3.7 & 0.8 \\
\hline \multicolumn{5}{|c|}{ HIV viral load (copies/ml) } \\
\hline$\leqslant 400$ & $2 / 10(20)$ & 1 & - & \\
\hline $401-5000$ & $2 / 8(25)$ & 1.3 & 0.1 to 12.4 & 0.9 \\
\hline $5001-55000$ & $13 / 21(62)$ & 6.5 & 1.1 to 38.6 & 0.05 \\
\hline$>55000$ & $8 / 9(89)$ & 32 & 2.4 to 428 & 0.005 \\
\hline \multicolumn{5}{|c|}{ CD $4+$ cell count $\left(\right.$ cells $/ \mathrm{mm}^{3}$ ) } \\
\hline$>500$ & $5 / 14(36)$ & 1 & - & \\
\hline $201-500$ & $10 / 17(59)$ & 2.6 & 0.6 to 11 & 0.3 \\
\hline$\leqslant 200$ & $12 / 20(60)$ & 2.7 & 0.7 to 11 & 0.3 \\
\hline \multicolumn{5}{|c|}{ AIDS diagnosis before admission } \\
\hline Yes & $6 / 12(50)$ & 1 & - & \\
\hline No & $23 / 43(53.5)$ & 1.1 & 0.3 to 4.1 & 0.9 \\
\hline
\end{tabular}


(median) (IQR: 2650-47000 copies/ml). The mean for CD4 cells at study entry was $422 \mathrm{cel} / \mathrm{mm}^{3} ; 16 \%$ (14 of 86) of patients had been diagnosed as having AIDS before admission (in 12 of 14 AIDS cases the defining illness was tuberculosis). Overall, the lifetime prevalence of ART use was $64 \%$ ( 55 of 86 ); $30 \%$ of them ( 26 of 86 ) were currently taking ART, and 34\% (29 of 86) had abandoned ART before admission (past ART use). Not surprisingly, there was a significant trend towards lower HIV viral load in current compared with past ART users $\left(3.4 v 4.4 \log _{10} ; \mathrm{p}<0.0001\right)$ and $35 \%$ ( 8 of 23 ) among current ART users had HIV viral load $\leqslant 400$ copies $/ \mathrm{ml}$.

Table 1 shows the odds (ORs with 95\% confidence intervals) for abandoning ART. Abandonment of ART did not appear to be associated with age, history of incarceration, duration of HIV infection, duration of intravenous drug use, antecedent of AIDS and CD4 cell count. However, cessation of ART was significantly higher in female IDUs $(87.5 \%)$ than in male IDUs (47\%) and women were 7.9 times more likely to abandon ART than men $(p=0.05)$ (95\%CI 0.9 to 69.8). HIV positive people with HIV viral load $>55000$ copies/ml were 32 times more likely to have interrupted ART compared with those who had HIV viral load $\leqslant 400$ copies/ml (OR 32; 95\%CI 2.4 to $428 ; \mathrm{p}=0.005)$.

\section{COMMENT}

Despite the small sample size of this cross sectional study and the lack of variables related to socioeconomic status, female IDUs are at increased risk of abandoning ART and, up to 50\% of AIDS patients with concurrent drug injection are not taking ART. Treatment of drug dependence, supervised ART, and appropriate health care facilities ${ }^{4-6}$ may help to ensure adherence to medication.

\section{Authors' affiliations}

R Muga, J M Egea, A Sanvisens, J Arnal, C Tural, J Tor, C Rey-Joly, Servicio de Medicina Interna, 4a planta, Hospital Universitari Germans Trias i Pujol, Badalona, Spain

Funding: this work was partially supported by grant Fondo de Investigación Sanitaria (FIS), Ministry of Health, Spain (grants 00/ 0294 and C03/005) and Fundació La Marató de TV3 (grant 02/1330).

Conflicts of interest: none declared.

Correspondence to: Dr R Muga, Hospital Universitari Germans Trias i Pujol, Servicio de Medicina Interna, 4a planta, Hospital Universitari Germans Trias i Pujol, Ctra. canyet s/n, 08916 Badalona, Spain; rmuga@ns.hugtip.scs.es

Accepted for publication 30 July 2003

\section{REFERENCES}

1 Carrieri MP, Moatt JP, Vlahov D, et al. Acces to antiretroviral treatment among French HIV infected injection drug users: the influence of continued drug use. J Epidemiol Community Health 1999;53:4-8.

2 Bassetti S, Battegay M, Furrer $\mathrm{H}$, et al. Why is highly active antiretroviral therapy (HAART) not prescribed or discontinued? Swiss HIV cohort study. J Acquir Immune Defic Syndr 1999:21:1 14-19.

3 Yerly S, Race E, Vora S, et al. HIV drug resistance and molecular epidemiology in patients with primary HIV infection. 8th Conference on retroviruses and opportunistic infectious. Chicago, Feb 2001:754.

4 Greenberg B, Berkman A, Thomas R, et al. Evaluating supervised HAART in late-state HIV among drug users: a preliminary report. J Urban Health 1999;76:468-80.

5 Fischl M, Rodriguez A, Scherpella E, et al. Impact of directly observed therapy on outcomes in HIV clinical trials. 7th Conference on retroviruses and opportunistic infections, San Francisco, 30 Jan 30-2 Feb 2000:71.

6 Tyndall M, Yip B, Hogg R, et al. Coverage, adherence, and sustainability of antiretroviral therapy among injection drug users in Vancouver, Canada. 13th International AIDS conference. Durban, South Africa, 2000:ThPeB4990. 